- ACORN Australan colege of | JOURNAL OF PERIOPERATIVE NURSING

\title{
Using the ACORN Standards: An exploration of claims, concerns and issues
}

Follow this and additional works at: https://www.journal.acorn.org.au/jpn

Part of the Health Services Administration Commons, Health Services Research Commons, Perioperative, Operating Room and Surgical Nursing Commons, and the Surgery Commons

(c) (1)

This work is licensed under a Creative Commons Attribution 4.0 License.

\section{Recommended Citation}

Williams, Carollyn; Duff, Jed Dr; Nicholson, Pat; Hamlin, Lois RN; and Gillespie, Brigid M. PhD (2018) "Using the ACORN Standards: An exploration of claims, concerns and issues," Journal of Perioperative Nursing: Vol. 31 : Iss. 4 , Article 5.

Available at: https://doi.org/10.26550/2209-1092.1050

https://www.journal.acorn.org.au/jpn/vol31/iss4/5

This Article is brought to you for free and open access by Journal of Perioperative Nursing. It has been accepted for inclusion in Journal of Perioperative Nursing by an authorized editor of Journal of Perioperative Nursing. 


\section{Authors}

Carollyn Williams

M Hlth SC (Nur), RN, FACN, FACORN

Barwon Health, Geelong, Vic

Associate Professor Jed Duff

PhD, RN, FACORN

School of Nursing and Midwifery, Faculty

of Health and Medicine, The University of Newcastle NSW

Associate Professor Pat Nicholson

PhD, RN, FACORN

School of Nursing and Midwifery, Centre

for Quality and Patient Safety Research,

Faculty of Health, Deakin University,

Geelong Vic

Dr Lois Hamlin

DNurs, RN, FACN, Foundation Fellow ACORN

formerly Senior Lecturer, Faculty of Health, UTS NSW

Professor Brigid M Gillespie

PhD, RN, FACORN

School of Nursing \& Midwifery, Griffith

University and Gold Coast Hospital and Health Service Qld

\section{Using the ACORN Standards: An exploration of claims, concerns and issues}

Findings from the Research workshop at the ACORN \& ASIORNA Conference in Adelaide
Abstract
An interactive action research workshop was offered during the ACORN \& ASIORNA Conference which was held in Adelaide in 2018. The purpose of the workshop was to explore the research evidence supporting ACORN's Standards for Perioperative Nursing in Australia, to identify gaps in the evidence related to standards and to explore challenges associated with the implementation of standards in clinical practice. The workshop also provided perioperative nurses with the opportunity to discuss their research interests and ask questions about undertaking research-focused degrees. Workshop participants provided an eclectic and credible range of issues related to the development and implementation of standards, underpinned by their concern for patient safety. In addition, the workshop outcomes have since provided the basis for the Research Committee to develop a research priorities survey to be distributed to the membership in the next 12 months.

\section{Background}
In 2017, the Australian College of Perioperative Nurses (ACORN, the
activity for the College. Its terms of reference are to:
- identify and support world class, established and emerging researchers to undertake rigorous research in perioperative nursing
- develop a community of perioperative researchers amongst whom collaboration can occur
- support emerging and established researchers to build capacity in the perioperative speciality
- encourage perioperative researchers to publish their work in peer-reviewed journals, for example the Journal of Perioperative Nursing, both nationally and internationally
- foster strategic collaborations with other like-minded research or professional bodies and within the philanthropic sector
- assess ACORN research grant applications using objective, predetermined criteria and making recommendations to the board accordingly
- assess submissions from researchers wanting to access members for their research and making recommendations to the board accordingly. College) established a Research subcommittee (RSC) to support and encourage research relating to perioperative nursing, to promote evidence-based practice and improve knowledge and learning. The primary function of the RSC is to guide and coordinate all aspects of research
To support and encourage perioperative nursing research, the RSC believe it is important to survey ACORN members and seek their feedback regarding research priorities. An important first step in this endeavour was to conduct a national research and networking 
session in the form of a research workshop at the ACORN \& ASIORNA Conference held in Adelaide from 23 to 26 May 2018.

\section{Research workshop}

The RSC members decided to use the Standards as a focal point to facilitate discussion and help to prioritise potential research activities for the College. Consequently, the aims of the workshop were to:

1. explore ACORN members' perceptions of the evidence base that informs standards

2. identify gaps in standards relative to the available evidence used to inform practice

3. identify practical issues in the implementation of standards in clinical practice

4. gauge participants' interest in undertaking research, and identifying any 'burning research questions'.

The workshop used an action research approach that was informed by critical social theory and applied a claims, concerns and issues $(\mathrm{CCl})$ framework ${ }^{1}$ to explore the questions posed. Action research is a participatory method used to investigate and solve issues. It allows participants to engage collaboratively to solve practice-based issues and uses interactive and creative techniques to explore and gather data regarding the issues under discussion? ${ }^{2}$.

The $\mathrm{CCl}$ framework allows the questions to be explored by examining three concepts:

1. Claims: these are any assertions that a stakeholder may make that are favourable.

2. Concerns: these are any assertions that are unfavourable. The purpose is to highlight potential barriers: personal, systematic or organisational, real or perceived.

3. Issues: these are reasonable questions raised through better understanding of claims and concerns and are drawn from the latter by using 'what' and 'how' questions.

After gathering the data from participants, the results were summarised under each component of the framework and presented to participants. Framing participants' comments in relation to claims, concerns and issues allowed them to reflect on the results. It enabled claims to be acknowledged, and concerns and issues to be shared, discussed and potentially addressed ${ }^{1}$. Presenting the workshop findings to the wider perioperative community in this article also adds to the participatory and collaborative nature of the action research methodology.

The workshop was conducted over one hour with 15 participants and three facilitators, the latter were members of the RSC. Three sets of questions were posed.

1. Are the Standards evidencebased? How do we know?

2. Do the Standards adequately cover practice? Is there anything missing?
3. What are some of the issues associated with using the Standards in practice? How can these issues be overcome?

Participants were asked to respond to each question in turn by making both favourable and unfavourable assertions and raising any questions they had. Responses were written on three different coloured sticky notes, used to separately denote the claims, concerns and issues, and posted onto wall charts (Figure 1). At the end of each question the notes were examined by the facilitators, themes were identified and the information shared with the participants. Time for discussion was allocated

\section{Outcomes}

\section{Are the Standards evidence- based? How do we know?}

The answers to this question (see Table 1) provided predominantly favourable assertions (claims) that the Standards are evidencedbased, fully referenced and undergo a rigorous review process. Unfavourable assertions (concerns) and questions (issues) related to recency of the literature included, differences in interpretation of state directives that often override the Standards and the availability of the Standards in clinical settings.

\begin{tabular}{|c|c|c|}
\hline Claims & Concerns & Issues \\
\hline $\begin{array}{l}\text { - } \text { evidence-based (8 } \\
\text { participants) } \\
\text { - } \text { rigorous process (2) } \\
\text { - referenced (2) } \\
\text { - use systematic } \\
\text { reviews }\end{array}$ & $\begin{array}{l}\text { - } \text { recency of literature (2) } \\
\text { - interpreted differently (2) } \\
\text { - state directives are used } \\
\text { in some states } \\
\text { - PPE consistency } \\
\text { (presumed language and } \\
\text { recommendations) }\end{array}$ & $\begin{array}{l}\text { - not accessible } \\
\text { to all } \\
\text { - legality of } \\
\text { standards } \\
\text { - are they reviewed } \\
\text { often enough? }\end{array}$ \\
\hline
\end{tabular}

PPE - personal protective equipment

Table 1: Are the Standards evidence-based? How do we know? 


\begin{tabular}{|c|c|c|}
\hline Claims & Concerns & Issues \\
\hline $\begin{array}{l}\text { - not sure } \\
\text { - yes, but the } \\
\text { Standards } \\
\text { can conflict } \\
\text { with state } \\
\text { directives; } \\
\text { sometimes } \\
\text { definitions } \\
\text { used in } \\
\text { standards are } \\
\text { too broad. }\end{array}$ & $\begin{array}{l}\text { - interpreted differently (3) } \\
\text { - sometimes too general to answer } \\
\text { specific questions (2) e.g. cloth hats } \\
\text { - the ACORN standards should show } \\
\text { a link to national standards } \\
\text { - do not cover unregistered staff } \\
\text { - credentialing } \\
\text { - guidance tool to develop to be HCF } \\
\text { specific } \\
\text { - mismatch between theoretical } \\
\text { practice and observed clinical } \\
\text { practice - the theory-practice gap }\end{array}$ & $\begin{array}{l}\text { - time delays to } \\
\text { synthesising } \\
\text { evidence into } \\
\text { practice (2) } \\
\text { e.g. preventing } \\
\text { hypothermia } \\
\text { - mandate } \\
\text { plume policy } \\
\text { - cover most } \\
\text { things but } \\
\text { always room } \\
\text { for change }\end{array}$ \\
\hline
\end{tabular}

Table 2: Do the Standards adequately cover practice? Is there anything missing?

2. Do the Standards adequately cover practice? Is there anything missing?

The answers to question two (see Table 2) indicated mostly unfavourable assertions and questions that related to what might be missing. These included different interpretations of the Standards; unclear links to the national standards; the generalised nature of the Standards relative to answering specific clinical questions (e.g., use of cloth hats); discrepancies between theory and actual clinical practice; the lack of coverage relative to unregistered staff; time delays in synthesising evidence into practice e.g. preventing hypothermia, and the lack of a guidance tool to assist in tailoring the Standards for use, relative to specific health care facilities (HCF).
3. What are some of the issues associated with using the Standards in practice? How can these issues be overcome?

Question three highlighted questions or issues (see Table 3). Again, access to the Standards was a concern that was identified, with the clash with state directives also noted. Failure to use the Standards was highlighted and various reasons for this were proffered. They included lack of management and education support, lack of consequence for their non-use, inconsistencies with other professional standards (e.g. Sterilising Research and Advisory Council of Australia) and poor knowledge of their existence by novices.

Suggestions were given to address these issues including various educational activities and initiatives, being proactive to increase awareness of the Standards and engaging in mentorship.

There were two final questions posed to the workshop participants, particularly those who were beginner researchers. The first sought their ideas about aspects of perioperative practice worthwhile researching.

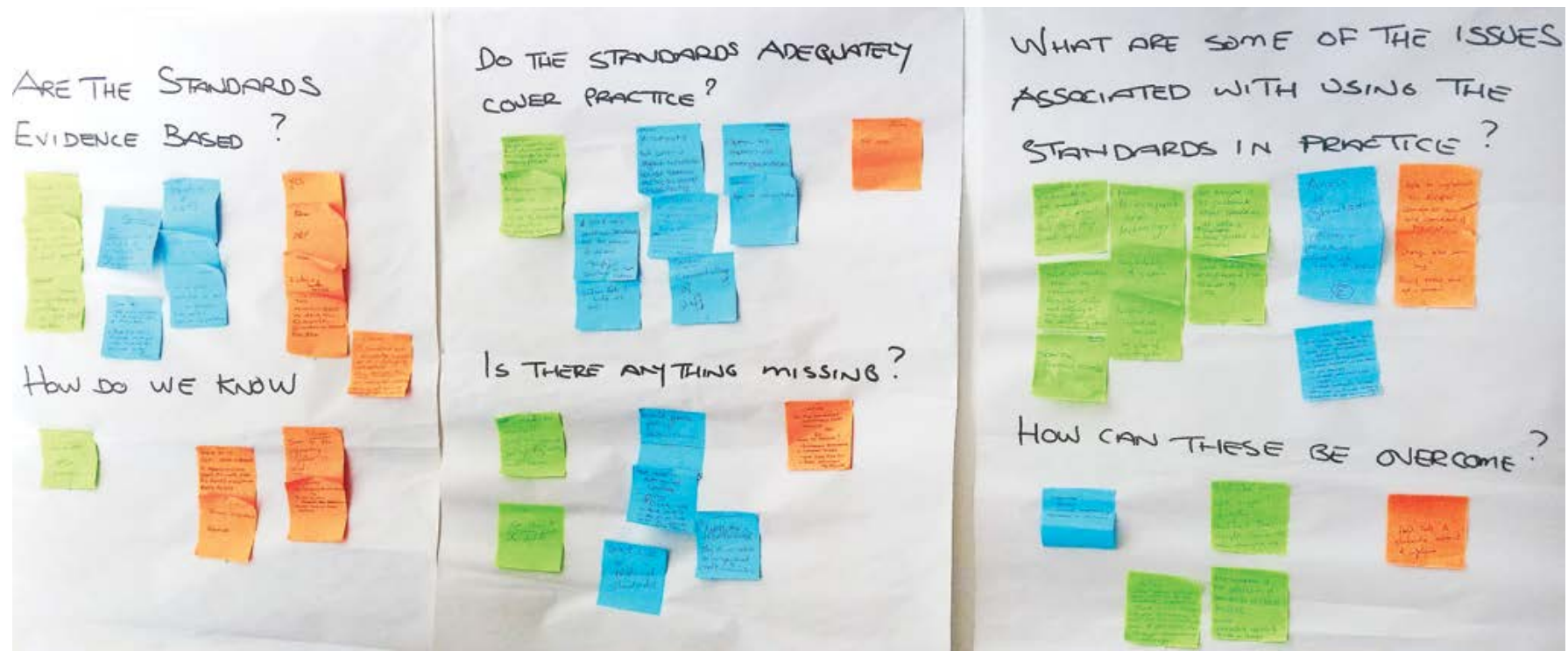

Figure 1: Posters with sticky notes. Orange notes are 'claims', blue notes are 'concerns' and green notes are 'issues'. 


\begin{tabular}{|c|c|c|}
\hline Claims & Concerns & Issues \\
\hline $\begin{array}{l}\text { - audit tool required } \\
\text { to standardise } \\
\text { compliance } \\
\text { - able to be } \\
\text { implemented as } \\
\text { considered 'gold' } \\
\text { standard } \\
\text { - change takes } \\
\text { so long (could } \\
\text { be overcome by } \\
\text { policy review and } \\
\text { education) }\end{array}$ & $\begin{array}{l}\text { - different state laws } \\
\text { - local culture, nurse } \\
\text { won't use EBP, other } \\
\text { team members won't } \\
\text { use standards } \\
\text { - access to the } \\
\text { Standards } \\
\text { - policies and } \\
\text { procedures direct link } \\
\text { to AORN (could be } \\
\text { overcome by mentors, } \\
\text { increasing importance } \\
\text { of the Standards to } \\
\text { individuals) }\end{array}$ & $\begin{array}{l}\text { - staff not reading or referring to the Standards } \\
\text { - variance in facility policy in not aligning to the Standards i.e. } \\
\text { not following them, no consequence } \\
\text { - managers and educators are weak - if you get in their face } \\
\text { they may wake up } \\
\text { - facility access } \\
\text { - management of poor application of standards (could be } \\
\text { overcome by interactive training or tools) } \\
\text { - novice nurses are not familiar with standards (could be } \\
\text { overcome by competency packages) } \\
\text { - difference between ACORN standards and others e.g. CSSU } \\
\text { - not everyone passionate about standards (could be overcome } \\
\text { by posters } \\
\text { - directly support facilities (to use the Standards) } \\
\text { - relevance e.g. size of facility } \\
\text { - searchability of e-version } \\
\text { - the Standards should facilitate the incorporation of new } \\
\text { technologies }\end{array}$ \\
\hline
\end{tabular}

CSSU - Central sterilising and supply unit

AORN - Association of periOperative Registered Nurses

EBP - evidence-based practice

Table 3: What are some of the issues associated with using the Standards in practice? How can these issues be overcome?

The second question asked them about the support they might require exploring research questions and/ or further research-related studies. The RSC facilitators also sought the permission of the participants to contact them to discuss their research queries. Of the 15 attendees, 11 participants opted to share their research queries.

Two of their topic areas for a research question were patientfocused; the remaining four related to perioperative nurses themselves. They are listed below.

Patient-focused research topics:

1. disruptive behaviour and effects on patient safety
2. integration of instrument tracking with documentation standard (electronic).

Perioperative nursing focussed research topics:

1. protecting OR nurses from cytotoxic patients

2. lived experience for new graduate nurses when implementing the ACORN standards in practice

3. bullying - a survey of ACORN members

4. obesity among nurses - protecting them from unhealthy lifestyles where shift work and night duty creates poor eating and exercise habits.
The support needed to undertake research, including research-based higher degrees elicited several responses, as follows:

- How do you embark on a PhD?

- How do you choose a good supervisor?

- Does ACORN provide research advice?

- How do you go ahead with research and how do you break through barriers in conducting research?

- How can we have a clear pathway for supporting publications and getting them recognised?

- Wanting support with masters' degree research subject - what is available? 


\section{Discussion}

The participants generally viewed the Standards favourably and acknowledged that the rigour of the process had improved over the years. It should be noted that the current process takes nine to twelve months and includes a series of rounds of review, comment and feedback between the Standards Editor, the Standards Committee, and external stakeholders ${ }^{3}$. However, improvements in rigour come at a cost. The process is time consuming and relies on the 'goodwill' of volunteers. It is uncertain whether this level of reliance on volunteers is sustainable over the longer term.

Having well-developed, evidencebased standards is a worthy achievement but this does not ensure that they are translated into routine clinical practice. Research and anecdotal evidence confirm that the act of synthesising evidence into standards is not enough to change practice. The participants in this workshop identified a host of barriers that prevented the uptake of the Standards and this is supported by research on the barriers Australian perioperative nurses face when introducing evidence-based practice ${ }^{4}$. The workshop participants rightly pointed out that the College needs to develop guideline tools and other material to help implement the Standards into practice. The College acknowledges this and its current focus on standards implementation ${ }^{5}$ is a positive step forward, in particular the development of the new Practice Audit Tools (available from: www.acorn.org.au/standards/ practice-audit-tools-pats).

There were criticisms from the workshop participants that some of the research informing standards was dated or of poor quality. Clearly, standards are only as good as the research that is available to inform them. To have the evidence to inform standards, the College needs researchers to investigate questions that are important to perioperative nurses, their work, and patient safety. The fact that 11 of the 15 participants had research queries, including specific ideas for a research question, may indicate that there is a growing interest in perioperative nursing research. Their responses and suggestions arising from the final workshop questions will be considered by the RSC, who will subsequently make recommendations to the ACORN board regarding subsequent research activities. That said, perioperative nursing appears to be lagging behind many other comparable specialties when it comes to participation in, and generation of, primary research. To strengthen the Standards, and in turn improve patient care, the College may need to focus on strategies to promote and celebrate perioperative nursing research and evidence-based practice. The introduction of the annual \$20 000 ACORN research grant is one way of promoting a research culture $^{6}$.

\section{Conclusions}

The research workshop provided the opportunity to further the work of the RSC and explore perioperative nurses' views about evidence for practice and implementing standards. Using a critical social theory framework, underpinned by participatory methodology, the workshop allowed the identification of perceived gaps in the use of standards and potential areas for further research. The workshop was also the means to communicate with ACORN members who are interested in exploring the evidence more successfully, becoming early researchers or exploring further study, and to establish contacts now and for future. This will allow the opportunity to support emerging researchers, develop a community of perioperative researchers and build research capacity in the perioperative speciality. It has also provided the basis for the RSC to develop a research priorities survey to be distributed to the membership via an email link.

\section{Acknowledgements}

Rebecca East

M(Periop), M(NP), BN, RN

Education and Research Committee Chair 2016-2018

Patricia Flood

MNursPrac, GDipNursPrac (Periop), BN, RN Research Committee Chair 2018-2020

\section{References}

1. McCormack B, Manley K. Evaluating practice developments. In McCormack B, Manley K, Garbett R. Practice Development in Nursing. Oxford: Blackwell Publishing; 2004, 83-117.

2. Whitehead D, Schneider Z. Mixed methods research. In Schneider Z, Whitehead D, LoBiondo-Wood G, Haber J. Nursing and Midwifery Research: Methods and appraisals for evidence-based practice. $4^{\text {th }}$ ed. Sydney: Mosby Elsevier; 2013, 263-284.

3. Osborne S, Levada L, Johnson J, Gore A, Ireland S, Nicholson P. Standards are living documents. Journal of Perioperative Nursing 2015;28(1):25-7.

4. Duff J, Butler M, Davies M, Williams R, Carlile J. Perioperative nurses' knowledge, practice attitude and perceived barriers to evidence use: A multisite, cross-sectional survey. Journal of Perioperative Nursing 2014;27(4):28-35.

5. Osborne S. Making evidence-based perioperative practices stick: An introduction to an implementation science approach. Journal of Perioperative Nursing 2017;30(4):52-55.

6. Gillespie BM. Promoting an evidencebased culture through recognition of the contribution of research to perioperative practice. Journal of Perioperative Nursing 2014;27(3):4-5 